\title{
GAMBARAN KARIES GIGI SERTA KEBIASAAN MAKAN MAKANAN KARIOGENIK PADA SISWA SDN 5 ABIANSEMAL TAHUN 2018
}

I Nyoman Wirata $^{1}$, Ni Wayan Arini ${ }^{2}$, Ni Nyoman Dew Supariani ${ }^{3}$, Kadek Diantini ${ }^{4}$

1,2,3 Dosen Jurusan Kesehatan Gigi Poltekkes Denpasar

4 Mahasiswa Jurusan Kesehatan Gigi

\begin{abstract}
School-aged children are one of the most vulnerable groups of caries, because they generally have lack of knowledge and behavior about oral health, such as the habit of consuming cariogenic foods that trigger the dental caries. The purpose of this research is to know the caries description and the habit of consuming cariogenic food in students of SDN 5 Abiansemal in 2018. The technique used in this research is descriptive technique with the number of respondents 44 students. The result of the research on 44 students of SDN 5 Abiansemal shows the average of caries permanent teeth in students of SDN 5 Abiansemal is 1,61. The permanent caries mode of teeth is the tooth 46 ( teeth first permanent mandibular molar of the right lower). The frequency of students who have the habit of consuming most cariogenic foods is moderate category ( 2 times a day) that is $52,3 \%$. The frequency of students with caries teeth based on the dietary habits of cariogenic foods isfrom 7 students who have the habit of eating cariogenic foods high ( $>3$ times a day) as many as 7 students $(100 \%)$ had caries teeth with an average dental caries 3,42 means that one student experiences three to four caries teeth. These results suggest that students who consume highcategorical cariogenic foods tend to experience more dental caries.
\end{abstract}

Keywords : Dental caries, cariogenic food,elementary school students

\section{Pendahuluan}

Tujuan pembangunan kesehatan menuju Indonesia Sehat 2025 adalah meningkatkan kesadaran, kemauan, dan kemampuan hidup sehat bagi setiap orang agar peningkatan derajat kesehatan masyarakat yang setinggitingginya. Kesehatan mulut merupakan bagian yang fundamental dari kesehatan secara menyeluruh. Tindakan pencegahan terhadap penyakit gigi dan mulut perlu dilakukan agar tidak terjadi gangguan fungsi, aktivitas serta penurunan produktifitas kerja yang mempengaruhi kualitas hidup'.

Budijanto 2005 menyatakan bahwa masalah terbesar yang dihadapi saat ini di bidang kesehatan gigi dan mulut adalah karies gigi. Karies gigi paling banyak dijumpai dalam rongga mulut bersama dengan penyakit periodontal $^{2}$. Karies gigi dapat dialami oleh setiap orang dan dapat timbul pada satu permukaan gigi atau lebih, serta dapat meluas ke bagian yang lebih dalam dari gigi, misalnya email ke dentin atau ke pulpa ${ }^{3}$.

Penelitian oleh Yuda (2016), di SD Negeri 2 Sedang dari 31 siswa yang mengalami karies gigi permanen sebanyak 22 orang $(70,97 \%)$ dan yang tidak mengalami karies gigi permanen sebanyak 9 orang $(29,03 \%)^{4}$. Penelitian yang dilakukan oleh Novianus (2015), di SDN Drangong I, SDN I Taktakan, dan SDN Pareng dari 140 siswa yang mengalami karies gigi permanen tinggi sebanyak 89 orang $(63,6 \%)$. Sedangkan siswa yang mengalami karies gigi permanen rendah, yaitu sebanyak 51 orang $(36,4 \%)^{\mathbf{5}}$.

Riset Kesehatan Dasar (2013), melaporkan bahwa penduduk di Provinsi Bali pada tahun 2013 memiliki masalah kesehatan gigi dan mulut sebesar $24.0 \%$, untuk 
kelompok umur 5-9 tahun sebesar 27,7\% dan kelompok umur 10-14 tahun sebesar 22,4\%. Riset Kesehatan Dasar (2013), melaporkan di Kabupaten Badung penduduk yang bermasalah dengan kesehatan gigi dan mulut dalam 12 bulan terakhir yaitu 31,6\% ${ }^{6}$.

Makanan manis yang mengandung gula membantu dalam pembentukan asam memicu terjadinya karies gigi. Konsumsi makanan kariogenik yang sering dan berulang-ulang akan menyebabkan $\mathrm{pH}$ plak dibawah normal dan menyebabkan demineralisasi enamel dan terjadilah pembentukan karies gigi ${ }^{7}$.

Menurut Besford dalam Inunu dan Sarasati (2005), mengatakan bahwa sepotong makanan manis dalam 12 menit dapat menyebabkan kerusakan gigi. Konsentrasi gula yang lebih banyak pada makanan manis tersebut akan menciptakan suasana yang lebih asam sehingga dapat memperburuk kerusakan gigi yang terjadi namun tidak mungkin memastikan batas aman konsentrasi bagi gula bagi kesehatan gigi. Variasi seperti durasi makanan manis yang ditelan, serta adanya rangsangan air liur, berpengaruh pada adanya penyusunan batas aman konsentrasi gula tersebut ${ }^{7}$.

Berdasarkan wawancara dengan beberapa siswa SDN 5 Abiansemal, setiap harinya siswa mengonsumsi makanan yang bersifat kariogenik dan setelah itu para siswa tidak makan buah atau tidak minum air putih melainkan minum minuman kemasan yang mengandung pemanis. Hasil wawancara dengan pedagang di kantin SDN 5 Abiansemal, diperoleh informasi bahwa kantin tersebut menyediakan berbagai macam makanan ringan yang manis dan berbagai makanan yang mengandung karbohidrat yang bersifat melekat karena siswa cenderung tertarik dan menyukai makanan seperti coklat, permen dan makanan yang bersifat kariogenik lainnya. Oleh karena itu peneliti tertarik untuk melakukan penelitian tentang "Gambaran Karies Gigi Serta Kebiasaan Makan Makanan Kariogenik Pada Siswa Kelas IV Dan V SDN 5 Abiansemal Tahun 2018”.
Tujuan pelitian untuk mengetahui gambaran karies gigi serta kebiasaan makan makanan kariogenik pada siswa kelas IV dan V SDN 5 Abiansemal tahun 2018.

\section{Metode Penelitian}

Jenis penelitian ini adalah penelitian diskriptif dengan desain survei. Bertempat di SDN 5 Abiansemal Kecamatan Abiansemal Kabupaten Badung pada bulan Juni 2018. Unit analisis pada penelitian ini adalah siswa kelas IV dan V SDN 5, dengan jumlah responden yang berjumlah 44 orang. Cara pengumpulan data data gigi karies dikumpulkan dengan cara memeriksa langsung terhadap responden kemudian hasil pemeriksaan ditulis ke dalam status pemeriksaan gigi, sedangkan data tentang kebiasaan makan makanan kariogenik dilakukan dengan melakukan wawancara dengan chek list.

\section{Hasil Penelitian}

Karakteristik subjek penelitian

Karakteristik subjek penelitian di SDN 5 Abiansemal berdasarkan jenis kelamin ditunjukan pada tabel 1 :

Tabel 1 Karakteristik Responden Berdasarkan Jenis Kelamin Tahun 2018

\begin{tabular}{clcc}
\hline No. & Jenis Kelamin & $\begin{array}{c}\text { Frekuensi } \\
\text { Siswa }\end{array}$ & $\%$ \\
\hline 1 & Laki-laki & 27 & 61,36 \\
2 & Perempuan & 17 & 38,64 \\
\hline & Jumlah & 44 & 100 \\
\hline
\end{tabular}

Tabel 1 menunjukan bahwa jenis kelamin responden lebih banyak laki-laki dengan jumlah 27 orang $(61,36 \%)$ dan hanya 17 orang $(38,64 \%)$ yang berjenis kelamin perempuan. 
Hasil pengamatan terhadap subjek penelitian

Rata-rata responden mengalami karies, dari 44 responden yang diperiksa, bahwa terdapat 71 gigi permanen yang mengalami karies dengan rata-rata karies gigi permanen sebesar 1,61.

Modus gigi permanen yang mengalami karies dapat dilihat pada tabel 2.

Tabel 2. Modus Gigi Permanent yang Mengalami Karies pada Siswa SDN 5 Abiansemal Tahun 2018

\begin{tabular}{cc}
\hline $\begin{array}{c}\text { Elemen gigi yang } \\
\text { terkena karies }\end{array}$ & Frekuensi siswa \\
\hline 13 & 1 \\
14 & 1 \\
15 & 1 \\
16 & 4 \\
23 & 1 \\
24 & 1 \\
26 & 8 \\
35 & 1 \\
36 & 21 \\
37 & 2 \\
45 & 2 \\
46 & 24 \\
47 & 4 \\
\hline Jumlah & 71 \\
\hline
\end{tabular}

Tabel 2 menunjukkan gigi permanen yang mengalami karies paling banyak adalah gigi 46 (gigi molar pertama permanen rahang atas kanan).

Frekuensi Siswa SDN 5 Abiansemal yang mempunyai kebiasaan makan makanan kariogenik.

Hasil penelitian yang dilakukan terhadap 44 siswa SDN 5 Abiansemal pada Bulan Juni Tahun 2018 menunjukkan bahwa frekuensi siswa yang mempunyai kebiasaan makan makanan kariogenik dapat dilihat pada tabel 3 .
Tabel 3. Frekuensi Siswa Kebiasaan Makan Makanan Kariogenik

\begin{tabular}{llcc}
\hline No. & $\begin{array}{l}\text { Kebiasaan makan } \\
\text { makanan } \\
\text { kariogenik }\end{array}$ & $\mathrm{f}$ & $\%$ \\
\hline 1 & $\begin{array}{l}\text { Tinggi ( } \geq 3 \text { kali } \\
\text { dalam sehari) }\end{array}$ & 7 & 16 \\
2 & $\begin{array}{l}\text { Sedang (2 kali } \\
\text { dalam sehari) }\end{array}$ & 23 & 52,3 \\
3 & $\begin{array}{l}\text { Rendah (1 kali } \\
\text { dalam sehari) }\end{array}$ & 14 & 31,7 \\
\hline Jumlah & 44 & 100 \\
\hline
\end{tabular}

Tabel 3 menunjukkan bahwa dari 44 siswa kelas IV dan V SDN 5 Abiansemal, frekuensi makan makanan kariogenik yang terbanyak adalah kategori sedang (2 kali dalam sehari) $(52,3 \%)$.

Frekuensi siswa SDN 5 Abiansemal yang mengalami gigi karies berdasarkan kebiasaan makan makanan kariogenik dapat dilihat pada tabel 4 .

Tabel 4. Frekuensi Siswa yang Mengalami Gigi Karies Berdasarkan Kebiasaan Makan Makanan Kariogenik

\begin{tabular}{|c|c|c|c|c|c|c|c|}
\hline \multirow{3}{*}{$\begin{array}{l}\text { Kebiasaan } \\
\text { Makan } \\
\text { Makanan } \\
\text { Kariogenik }\end{array}$} & \multirow{2}{*}{\multicolumn{2}{|c|}{$\begin{array}{c}\text { Tidak } \\
\text { Karies }\end{array}$}} & \multirow{2}{*}{\multicolumn{2}{|c|}{ Karies }} & \multirow{3}{*}{$\begin{array}{l}\text { Jlh. } \\
\text { Siswa }\end{array}$} & \multirow{3}{*}{$\%$} & \multirow{3}{*}{$\begin{array}{l}\overline{\mathrm{X}}_{\text {Gigi }} \\
\text { Karies }\end{array}$} \\
\hline & & & & & & & \\
\hline & $\mathrm{f}$ & $\%$ & f & $\%$ & & & \\
\hline $\begin{array}{l}\text { Tinggi ( } \geq 3 \text { kali } \\
\text { dalam sehari) }\end{array}$ & 0 & 0 & 7 & 100 & 7 & 100 & 3,42 \\
\hline $\begin{array}{l}\text { Sedang ( } 2 \text { kali } \\
\text { dalam sehari) }\end{array}$ & 4 & 17,3 & 19 & 82,7 & 23 & 100 & 1,65 \\
\hline $\begin{array}{l}\text { Rendah (1 kali } \\
\text { dalam sehari) }\end{array}$ & 8 & 57,1 & 6 & 42,9 & 14 & 100 & 0,57 \\
\hline Total & 12 & & 32 & & 44 & & \\
\hline
\end{tabular}

Tabel 6 menunjukkan siswa dengan kebiasaan makan makanan kariogenik dengan kebiasaan tinggi ( $(\geq 3$ kali dalam sehari) sebanyak 7 siswa mengalami karies (100\%) dengan rata-rata gigi karies 3,42, sedangkan dari 14 siswa yang memiliki kebiasaan makan makanan kariogenik rendah hanya 6 siswa yang mengalami gigi karies $(42,9 \%)$ dengan rata-rata gigi karies 0,57. 


\section{Pembahasan}

Berdasarkan hasil penelitian diperoleh rata-rata gigi permanen yang mengalami karies yaitu 1,61. Nilai rata-rata tersebut lebih tinggi dari Target Nasional Indonesia tahun 2020 yaitu $\leq 1$. Hasil penelitian ini didukung oleh penelitian Yuda di SD Negeri 2 Sedang Tahun 2016 yang mendapatkan rata-rata gigi permanen yang mengalami karies $2,41^{4}$. Hal ini kemungkinan disebabkan karena siswa sering mengonsumsi makanan yang manis dan melekat yang dijual di kantin sekolah seperti permen dan coklat. Sesuai dengan pernyataan Suwelo (1992), salah satu faktor yang mempengaruhi gigi karies adalah substrat. Substrat adalah campuran makanan halus dan minuman yang dimakan sehari-hari dan menempel di permukaan gigi. Substrat berpengaruh terhadap karies secara lokal di dalam mulut ${ }^{8}$. Modus gigi permanen yang mengalami karies pada siswa kelas IV dan V SDN 5 Abiansemal adalah gigi 46 (gigi molar pertama permanen rahang atas kanan). Hasil ini sejalan dengan penelitian yang dilakukan Dewi di SD negeri 1 Dawan Kaler Kabupaten Klungkung tahun 2017 menyatakan bahwa gigi permanen yang paling banyak mengalami karies adalah gigi 46 (gigi molar pertama permanen rahang atas kanan) ${ }^{\mathbf{9}}$. Menurut Yoga dalam Sriyono (2009), gigi molar pertama permanen mudah terserang karies karena bentuk anatomisnya, permukaannya mempunyai pit dan fissure yang memudahkan retensi makanan dan merupakan tempat ideal bagi pertumbuhan bakteri penyebab karies ${ }^{1}$. Sulit bagi anak membersihkan secara baik daerah pit dan fissure gigi molarnya dengan sikat gigi, karena sebagian besar bagian dalam pit dan fissure tidak dapat dicapai bulu sikat gigi, hal inilah yang menyebabkan gigi molar pertama permanen paling mudah terkena karies.

Hasil penelitian yang dilakukan pada siswa kelas IV dan V SDN 5 Abiansemal diperoleh bahwa frekuensi siswa yang mempunyai kebiasaan makan makanan kariogenik tinggi ( $\geq 3$ kali dalam sehari) yaitu
7 siswa (16\%), yang mempunyai kebiasaan makan makanan kariogenik sedang (2 kali dalam sehari) yaitu 23 siswa $(52,3 \%)$, dan yang mempunyai kebiasaan makan makanan kariogenik rendah (1 kali dalam sehari) yaitu 14 siswa $(31,7 \%)$. Hal ini menunjukkan bahwa frekuensi makan makanan kariogenik yang terbanyak adalah kategori sedang ( 2 kali dalam sehari) yaitu: 52,3\%. Ini sejalan dengan penelitian yang dilakukan oleh Talibo, Mulyadi dan Yolanda (2016) di SDN 1 dan 2 Sonuo, Sulawesi Utara yang menyatakan bahwa frekuensi makanan kariogenik pada siswa kelas IV dan V yang terbanyak adalah kategori sedang ${ }^{\mathbf{1 0}}$. Hal ini disebabkan karena pada usia sekolah anak-anak lebih suka dengan makanan yang bersifat kariogenik dibandingkan dengan makanan yang berserat dan berair seperti: buah-buahan dan sayursayuran (Inunu dan Sarasati, 2005) ${ }^{7}$.

Frekuensi siswa yang mengalami gigi karies berdasarkan kebiasaan makan makanan kariogenik pada kelas IV dan V SDN 5 Abiansemal Tahun 2018 yaitu dari 7 siswa yang mempunyai kebiasaan makan makanan kariogenik dengan kategori tinggi ( $\geq 3$ kali dalam sehari) sebanyak 7 siswa (100\%) mengalami gigi karies dengan rata-rata gigi karies 3,42, dari 23 siswa yang mempunyai kebiasaan makan makanan kariogenik dengan kategori sedang (2 kali dalam sehari) sebanyak 19 siswa $(82,7 \%)$ yang mengalami karies dengan rata-rata gigi karies 1,65 sedangkan dari 14 siswa yang memiliki kebiasaan makan makanan kariogenik rendah hanya 6 siswa $(42,9 \%)$ yang mengalami gigi karies dengan rata-rata 0,57. Hasil ini menunjukkan bahwa siswa yang makan makanan kariogenik dengan kategori tinggi cenderung mengalami gigi karies lebih banyak. Hal ini sejalan dengan penelitian yang dilakukan oleh Paramartha pada siswa kelas IV dan V di SD Negeri 2 Singapadu Kaler tahun 2015 yang menyatakan bahwa dari 17 siswa yang yang makan makanan kariogenik dengan kategori tinggi ( $\geq 3$ kali dalam sehari) sebanyak 17 siswa $(100 \%)$ yang mengalami gigi karies ${ }^{11}$. Menurut Maulani 
dan Enterprice (2005), aktivitas gigi karies dapat meningkat karena konsumsi gula yang sudah melekat di permukaan gigi. Semakin sering mengkonsumsi gula di antara waktu makan, resiko terjadinya karies semakin meningkat karena sisa makanan membentuk plak kemudian menghasilkan asam dengan $\mathrm{pH}$ di bawah 5,5 maka terjadilah kerusakan email gigi sebagai tahap awal munculnya terjadinya karies ${ }^{\mathbf{1 2}}$.

\section{Simpulan}

Berdasarkan hasil penelitian gambaran gigi karies serta kebiasaan makan makanan kariogenik pada siswa kelas IV dan V SDN 5 Abiansemal tahun 2018 dapat disimpulkan bahwa rata-rata gigi permanen yang mengalami karies yaitu 1,61. Modus gigi permanen yang mengalami karies pada siswa kelas IV dan V SDN 5 Abiansemal adalah gigi 46 (gigi molar pertama permanen rahang atas kanan). Frekuensi siswa yang memiliki kebiasaan mengkonsumsi makan makanan kariogenik paling banyak adalah dengan kategori sedang (2 kali dalam sehari) yaitu: $52,3 \%$. Frekuensi siswa yang mengalami gigi karies berdasarkan kebiasaan makan makanan kariogenik pada kelas IV dan V SDN 5 Abiansemal tahun 2018 yaitu dari 7 siswa yang memiliki kebiasaan makan makanan kariogenik dengan kategori tinggi $(\geq 3$ kali dalam sehari) sebanyak 7 siswa $(100 \%)$ mengalami gigi karies dengan rata-rata gigi karies 3,42 artinya satu siswa mengalami tiga sampai empat gigi yang mengalami karies. Hasil ini menunjukkan bahwa siswa yang makan makanan kariogenik dengan kategori tinggi cenderung mengalami gigi karies lebih banyak.

\section{Saran}

Berdasarkan simpulan di atas, penulis dapat memberikan saran sebagai berikut:

Guru diharapkan memberikan informasi kepada siswa untuk memperhatikan kebersihan gigi dan mulut supaya siswa terhindar dari penyakit gigi dan mulut
Pihak sekolah SDN 5 Abiansemal, diharapkan untuk memperbanyak buku yang ada di perpustakaan sekolah dengan buku bacaan tentang kesehatan gigi dan mulut.

Tenaga kesehatan gigi Puskesmas Abiansemal 1 diharapkan meningkatkan upaya promotif pemeliharaan kesehatan gigi dan mulut dan gigi berlubang.

\section{Daftar Pustaka}

1. Sriyono, N.W. 2009. Pencegahan Penyakit Gigi dan Mulut Guna Meningkatkan Kualitas Hidup, Yogyakarta: UGM.

2. Budijanto, D. 2015. 93 Juta Lebih Penduduk Indonesia Menderita Karies Aktif. Tersedia dalam: http://www.kompasiana.com. Diakses pada 9 April 2018.

3. Tarigan, R. 2014. Karies Gigi. Jakarta: Hipokrates.

4. Yuda, A.D. 2016. Gambaran Karies Gigi dan perilaku Menyikat Gigi pada Siswa Kelas V SDN 2 Sedang Abiansemal Badung Tahun 2016. Denpasar: JKG Poltekkes Denpasar. (Karya Tulis Ilmiah). T.p.

5. Novianus, N. 2015. Hubungan Karakteristik dan Konsumsi Makanan Kariogenik dengan Kejadian Karies Gigi Permanen pada Siswa Umur 11-12 Tahun di Sekolah Dasar Negeri Terpilih Wilayah Kerja Puskesmas Taktakan Kota Serang. Tersedia dalam: https://journal.uhamka.ac.id. Diakses pada 9 April 2018.

6. Pranata, S., dkk. 2013. Riskesdas. Edisi 1. Jakarta: Lembaga Penerbitan Badan Penelitian dan Pengembangan Kesehatan Kementerian Kesehatan RI. 
7. Kartikasari, Y.H. 2014. Hubungan

Konsumsi Makanan Kariogenik dengan Kejadian Karies Gigi dan Status Gizi Pada Anak Kelas III dan IV SDN Kadipaten I dan II Kabupaten Bojonegoro. Tesis. Semarang: t.p

8. Suwelo, I.S. 1992. Karies Gigi pada Anak Dengan Pelbagia Faktor Etiologi. Jakarta: EGC.

9. Dewi, S.I. 2017. Perilaku Makan Permen dan Gambaran Karies Gigi Pada Siswa SD Negeri 1 Dawan Kaler Kabupaten Klungkung Tahun 2017. Denpasar: JKG Poltekkes Denpasar. (Karya Tulis Ilmiah). T.p.

10. Talibo, R.S., Mulyadi.,dan Yolanda, B. 2015. Hubungan Frekuensi Konsumsi Makanan Kariogenik dan Kebiasaan Menggosok Gigi dengan kejadian Karies Gigi pada siswa kelas IV-V SDN 1 \& 2 Sonuo, Sulawesi Utara. Tersedia dalam: https://journal.uhamka.ac.id. Diakses pada 23 Juni 2018.

11. Paramartha, A. 2015. Gambaran Gigi Karies dan Kebiasaan Makan Makanan Kariogenik pada Siswa SD Negeri 2 Singapadu Kaler Tahun 2015. Denpasar: JKG Poltekkes Denpasar. (Karya Tulis Ilmiah). T.p.

12. Maulani dan Enterprise. J. 2005. Kiat Merawat Gigi Anak. Jakarta: Gramedia 